\title{
Interactive comment on "Long-term multi-source data analysis about the characteristics of aerosol optical properties and types over Australia" by Xingchuan Yang et al.
}

\section{Anonymous Referee \#2}

Received and published: 13 December 2020

This paper analyzes the aerosol optical properties, aerosol types, aerosol vertical distribution as well as their spatiotemporal distributions over Australia using observational/reanalysis data from AERONET MODIS, MERRA-2, and CALIOP. This work provides useful information for researchers who are interested in the aerosol properties in Australia. I have the following comments and suggestions which need to be addressed before the paper can be accepted for publication.

1. Abstract: Line 13-16: Please specify what time periods the trends are for. Line 22-26: Please specify which heights these descriptions refer to since you are talking about $0.5-5 \mathrm{~km}$ heights in the sentence that follows. Line 26-27: Which region does 
this sentence refer to? Line 27-28: The meaning of this sentence is very vague. Line 28-30: This sentence seems to repeat the one in Line 23-26. Please rewritten Line 22-30 to make the meaning clear and avoid overlap.

2. Section 2.2.1: Line 104-106: Does this affect the trend analysis? You may want to do a sensitivity analysis using level 1.5 data for all years and compare with the present results.

3. Section 2.3: Line 146-148: Clarify what data sources you used to determine the aerosol types.

4. Section 3.1.1: Whenever you describe a trend, please specify what time period the trend is for. A trend without a time period is difficult to interpret. Please also describe whether the trends are statistically significant or not. Also, please try to explain why AODs present increasing or decreasing trends at the nine sites. Line 166-167: It is not appropriate to use "trend" for only two years.

5. Section 3.1.2: Please explain why AODs at the nine sites are generally high in spring and summer and low in fall and winter, before explaining why some sites peak in spring and others peak in summer. Line 230: What "marine biogenic emissions" are these? Are they sea-spray aerosols? I doubt whether "biogenic" is an appropriate term here. Line 237: I suggest you avoid using "trend" here. This is confusing since you used "trend" represent interannual trend in the last section.

6. Section 3.2.2: I think a lot of descriptions in the first paragraph are based on Figure 15 , but this figure is not cited until the next paragraph. Line 246: Is it really "intercontinental transport"? I think the sentences below do not actually talk about transport from other continents.

7. Section 3.2.3: Please comment on whether the distribution of MERRA-2 based aerosol compositions are consistent with the AERONET based aerosol types.

Printer-friendly version

8. Section 3.3: Whenever possible, please try to make connections between the 
CALIPSO based aerosol types and the AERONET based aerosol types used in previous sections. Second paragraph: please clarify that this paragraph describes the vertical profiles averaged across Austria, not one of the three regions defined in the last paragraph.

9. Figure 15: Clarify that the aerosol types are derived from AERONET.

Interactive

comment

Interactive comment on Atmos. Chem. Phys. Discuss., https://doi.org/10.5194/acp-2020-921, 2020. 